\title{
Caracterización morfológica del hígado del carpincho (Hydrochoerus hydrochaeris)
}

\author{
Cao, J.A.; Flores, C.I.; Bode, F.F.; Resoagli, J.M.; Fernández, J.A. \\ Cátedra de Anatomía I, Facultad de Ciencias Veterinarias, UNNE. \\ Sargento Cabral 2139, Corrientes (3400), Argentina. \\ Tel.379-4425753, E-mail: anato1@vet.unne.edu.ar
}

\begin{abstract}
Resumen
Cao, J.A.; Flores, C.I.; Bode, F.F.; Resoagli, J.M.; Fernández, J.A.: Caracterización morfológica del hígado del carpincho (Hydrochoerus hydrochaeris). Rev. vet. 28: 1, 47-50, 2017. El carpincho es un mamífero roedor de gran tamaño y constituye un recurso importante en el nordeste argentino como fuente potencial de proteína animal y de subproductos como el cuero, que pueden ser utilizados como importantes ingresos económicos a través de un manejo sustentable. En regiones donde se los cría con fines productivos, la actividad se ve favorecida por los numerosos estudios realizados sobre los parásitos que los afectan, las características de su piel y la morfología de su tubo digestivo. Sin embargo no se encontraron estudios que caractericen la morfología hepática. Anatómicamente el hígado del carpincho es grueso centralmente, la circunferencia es delgada y cortada por fisuras profundas, la división del hígado en lóbulos es completa, similar a la observada en los carnívoros, existiendo cinco lóbulos solapados entre sí. Presenta arquitectura lobulillar y espacios porta constituidos por estructuras vasculares y canaliculares biliares. Los lobulillos hepáticos no presentan la forma poligonal característica y sus límites están mal definidos. Las células hepáticas son irregularmente poliédricas, de tamaño variable y citoplasma eosinófilo, con un núcleo redondeado, central, basófilo, con cromatina laxa y nucléolo evidente. La organización histológica del órgano mantiene similitud con las descripciones efectuadas en mamíferos domésticos y roedores de experimentación.
\end{abstract}

Palabras clave: carpincho, hígado, estructura anatómica e histológica.

\begin{abstract}
Cao, J.A.; Flores, C.I.; Bode, F.F.; Resoagli, J.M.; Fernández, J.A.: Morphological characterization of the liver of "capybara" (Hydrochoerus hydrochaeris). Rev. vet. 28: 1, 47-50, 2017. Capybara is a large mammal rodent that inhabits the Argentinean territory. The species is an important source of animal protein and its skin is an important by-product which can be considered as an economic resource for sustainable utilization, as evidenced by the numerous studies on the capybara regarding parasitical diseases, characteristics of the skin and morphology of the digestive tract, and others. However, no studies that characterize the morphology of the liver have been found. Anatomically, the liver of capybara is thick and similar to that of carnivores, having five lobes overlapping each other. It presents lobular architecture and portal tracts consisting of vascular structures and bile canaliculi. Liver lobules do not exhibit the characteristic polygonal shape and their boundaries are poorly defined. Liver cells are irregularly polyhedral, variable in size, being the cytoplasm eosinophil, with a rounded, central, basophilic nucleus with dispersed chromatin and evident nucleolus. Histological organization of the organ keeps similarity with the descriptions of that of domestic mammals and experimental rodents.
\end{abstract}

Key words: capybara, liver, anatomical and histological structure.

\section{INTRODUCCIÓN}

El carpincho (Hydrochoerus hidrochaeris) es el roedor de mayor talla y está presente en todos los países sudamericanos a excepción de Chile. Es un componente

Recibido: 22 julio 2016 / Aceptado: 8 septiembre 2016 de la fauna de la Provincia de Corrientes y constituye un recurso importante en el ámbito regional como fuente potencial de proteína animal. Su cuero es un valioso subproducto, que puede ser transformado en ingreso económico a través de una utilización sustentable ${ }^{4}$.

Numerosos estudios realizados en Venezuela y Brasil abarcan aspectos anatómicos e histológicos del 
sistema genital de la hembra del "chigüire", así como descripciones detalladas del estómago ${ }^{1}$. No obstante, la mayoría de los estudios del sistema digestivo están orientados principalmente al ciego, debido a la importancia que asume en el proceso de la digestión, por ser el carpincho un herbívoro monocavitario ${ }^{5}$. No se hallaron informaciones sobre las glándulas salivares, hígado y páncreas.

El hígado es la glándula de mayor tamaño del cuerpo y lleva a cabo actividades fundamentales, siendo el órgano más trascendente en el metabolismo de los hidratos de carbono, las proteínas y las grasas, así como en la eliminación de las sustancias nocivas del cuerpo ${ }^{8}$. La función metabólica es más importante que la secretora, por lo cual la estructura del hígado se basa en las relaciones con los vasos sanguíneos, más que con los conductos secretores.

En los herbívoros el hígado representa entre el $1 \mathrm{y}$ $1,5 \%$ del peso corporal ${ }^{8}$. Cuando es comparado entre especies, presenta diferencias tanto en su forma como en su posición; sin embargo, en todos los animales se localiza adyacente al diafragma, en el hipocondrio derecho ${ }^{6}$. Su forma no es constante, dado que su función depende de una disposición interna adecuada, así como una masa suficiente ${ }^{9}$. El órgano se encuentra lobulado y cada lóbulo está cubierto por mesotelio, debajo del cual existe una capa delgada de tejido conectivo, la cápsula de Glisson.

Cada lóbulo se divide en numerosos lobulillos constituidos por sinusoides y placas de células parenquimatosas, los hepatocitos. Estos últimos se organizan radialmente alrededor de una vena central. Los lobulillos están mal definidos en la mayoría de las especies excepto el cerdo, en el cual sus límites son muy precisos gracias al abundante tejido conectivo que los separa $^{2}$.

Entre los roedores silvestres fue estudiado el hígado de cobayo (Cavia porcellus), el cual no mostró diferencias significativas en la estructura general del órgano, al ser comparado con otros mamíferos domésticos ${ }^{10}$.

El objetivo de este estudio fue caracterizar aspectos anatómicos e histológicos del hígado de $H$. hidrochaeris, a fin de establecer parámetros estructurales normales para posteriores estudios anatomopatológicos.

\section{MATERIAL Y MÉTODOS}

Se utilizaron ejemplares adultos de ambos sexos provenientes de los Esteros del Iberá (Corrientes, Argentina), capturados por medio de dardos anestésicos. Realizada la eutanasia, el hígado fue recuperado para su estudio anatómico-histológico.

Los criterios para la división del hígado en lóbulos, fueron los siguientes: $1^{\circ}$ ) los ligamentos falciforme y redondo separan el lóbulo izquierdo del lóbulo medio; $2^{\circ}$ ) la vesícula biliar separa el lóbulo medio del lóbulo derecho; $3^{\circ}$ ) el lóbulo medio está dividido en dos porciones por la cisura porta: una parte dorsal o lóbulo caudado y una ventral o lóbulo cuadrado; $4^{\circ}$ ) el lóbulo caudado se eleva constituyendo el proceso papilar, extendiéndose hacia la derecha de forma estrecha, como proceso caudado.

Para el estudio histológico se separaron pequeños fragmentos de tejido que fueron fijados en formol tamponado durante $24 \mathrm{~h}$. Posteriormente se deshidrataron, impregnaron e incluyeron en parafina. Los cortes, de 5 micrómetros de espesor, fueron realizados en micrótomo tipo Minot y se colorearon con HyE, Tricrómica de Mallory y PAS.

Se registraron fotográficamente las imágenes macro y microscópicas. El análisis de estas últimas se realizó con el programa Image Pro Plus versión 4.5 determinándose el diámetro de los hepatocitos, área celular y relación núcleo/citoplasma.

\section{RESULTADOS Y DISCUSIÓN}

La forma del hígado fue constante. Se estima que no es necesario que así sea pues su función depende de una disposición interna adecuada y masa suficiente ${ }^{9}$. Tradicionalmente, se establece que para homologar las porciones o lóbulos del hígado en los distintos mamíferos, se deben comparar con las divisiones del órgano en el hombre ${ }^{11}$.

En este trabajo se observó que el hígado del carpincho fue grueso centralmente, la circunferencia delgada y cortada por fisuras profundas que prácticamente alcanzaron la fisura portal a excepción de la que separó el lóbulo medial izquierdo del lóbulo cuadrado. Existieron 5 lóbulos principales solapados entre sí en una considerable extensión. Esta lobulación completa fue similar a la observada en los carnívoros domésticos ${ }^{7,8}$.

El lóbulo lateral izquierdo fue el de mayor tamaño y tuvo un contorno oval. El lóbulo medial izquierdo asumió un tamaño intermedio, el lóbulo cuadrado tuvo forma de lengua y el lóbulo medial derecho, fue el segundo en tamaño. El lóbulo lateral derecho fue el más pequeño; en la superficie visceral se situó el lóbulo caudado, formado por dos partes; la apófisis caudada a la derecha y la apófisis papilar a la izquierda, ambas subdivididas por fisuras secundarias. La vesícula biliar no alcanzó el borde ventral y asentó en la fosa para la misma, situada entre el lóbulo medial derecho y el cuadrado (Figura 1).

La superficie diafragmática fue convexa y se unió al diafragma mediante los ligamentos coronarios derecho e izquierdo, los cuales se conectaron ventralmente en el ligamento falciforme. Estos ligamentos se encontraron bien desarrollados. La impresión esofágica fue profunda (Figura 2).

Externamente, cada lóbulo hepático estuvo rodeado de una delgada capa de tejido conectivo (Figura 3). Histológicamente los lóbulos presentaron arquitectura lobulillar y espacios porta constituidos por estructuras vasculares y canaliculares biliares. Internamente este tejido fue escaso y se halló preponderantemente alrededor de la vena central y de los espacios portales. 


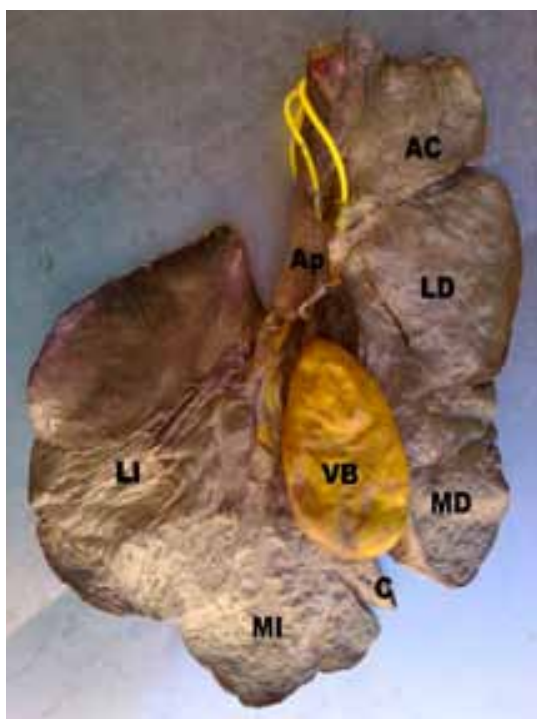

Figura 1. Superficie visceral del hígado. AC: apófisis caudada, Ap: apófisis papilar, LD: lóbulo lateral derecho, MD: lóbulo medial derecho, VB: vesícula biliar, LI: lóbulo lateral izquierdo, MI: lóbulo medial izquierdo.

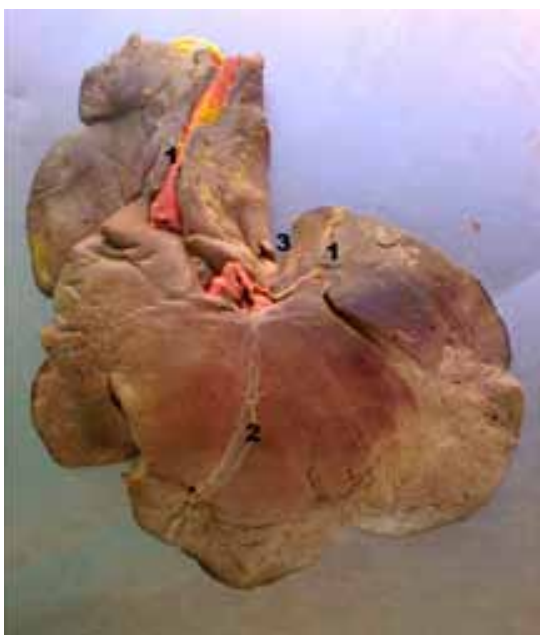

Figura 2. Superficie diafragmática del hígado. 1: ligamentos coronarios. 2: ligamento falciorme. 3: impresión esofágica.

Los lobulillos hepáticos no presentaron la forma poligonal característica y sus límites estuvieron mal definidos (Figura 4), a diferencia de los lobulillos hepáticos del perro y el gato, que son fácilmente reconocibles como aéreas hexagonales de $1 \mathrm{~mm}$ aproximadamente ${ }^{8}$. En los cobayos (C. porcellus) el hígado está compuesto de lobulillos hexagonales u ovalados, de $684 \mu \mathrm{m}$ de diámetro, incompletos y separados por tejido conjuntivo ${ }^{3}$.

En el espacio porta se encontraron estructuras vasculares con sus endotelios rodeados de fibras musculares lisas. La vena central se observó como un área ópticamente vacía rodeada por endotelio y, en algunos casos, pudieron observarse eritrocitos en su interior (Figura 5).

Los cordones son secciones de placas celulares alrededor de los sinusoides. En sus puntos de mayor

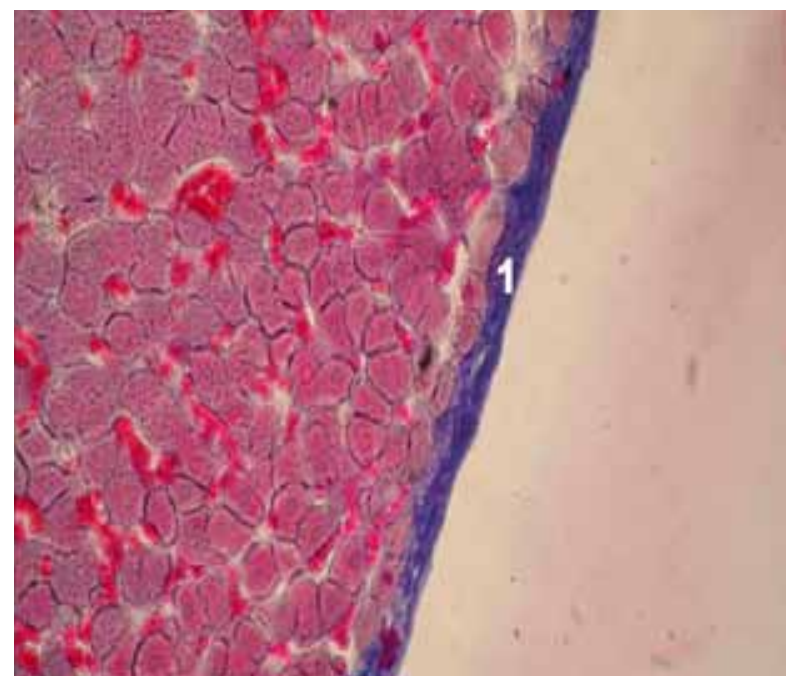

Figura 3. Cápsula de Glisson (1). Mallory 40X.

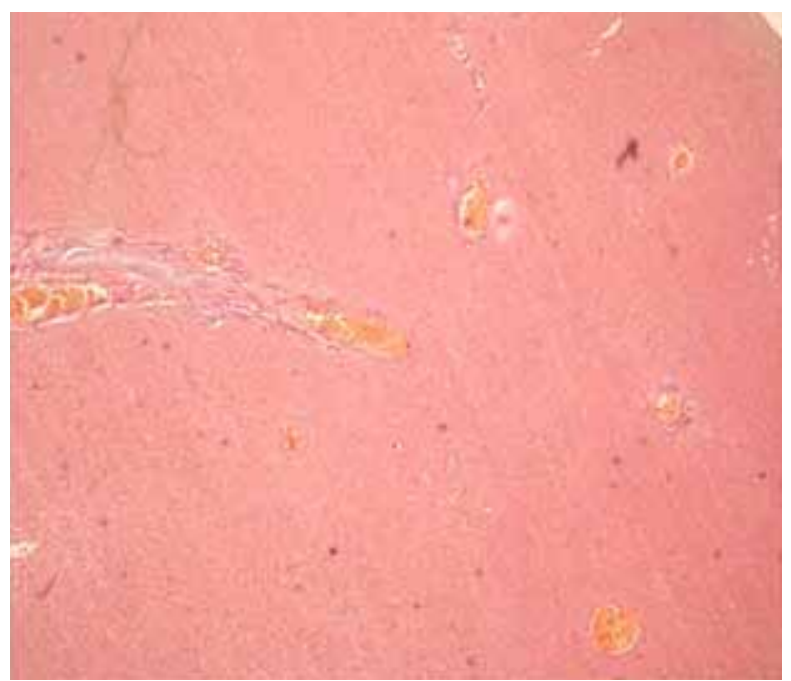

Figura 4. Lobulillos hepáticos. HyE 4X.

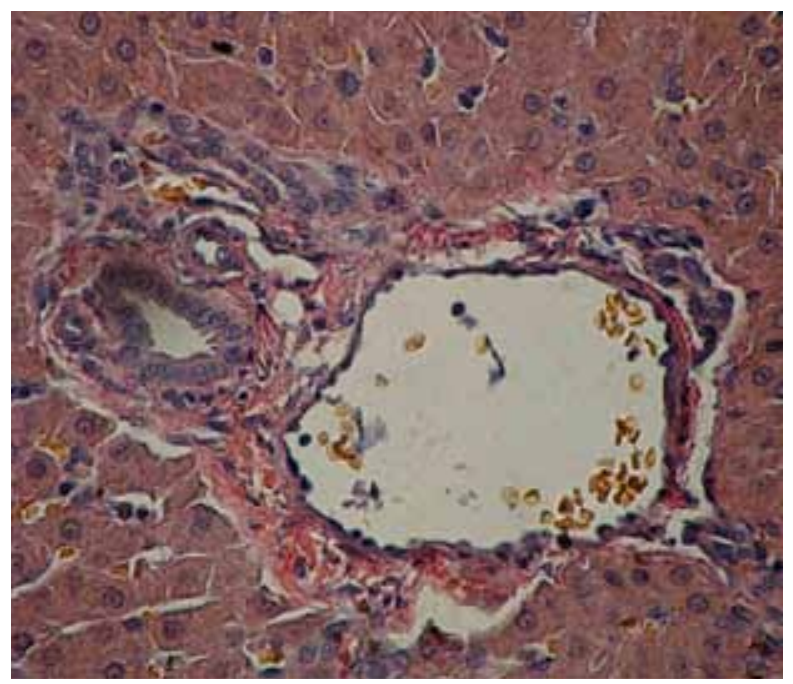

Figura 5. Células hepáticas. HyE 40X.

espesor, dichas placas no suelen tener más de dos células, de modo que cada una establece contacto con el sinusoide por una u otra cara; en los mamíferos, este espesor es de solamente una célula ${ }^{9}$. Otros animales domésticos incluirían hasta tres células por trabécula, 


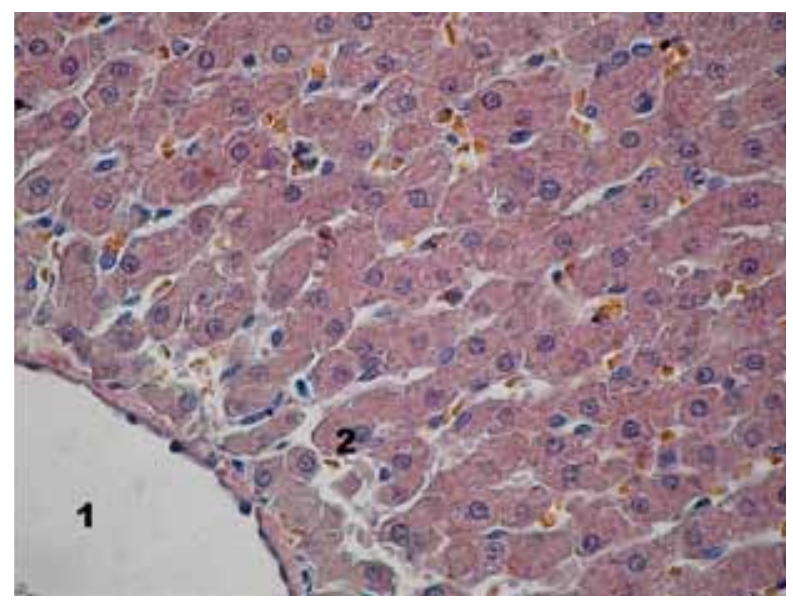

Figura 6. Vena central (1) y cordones celulares (2). HyE 40 X.

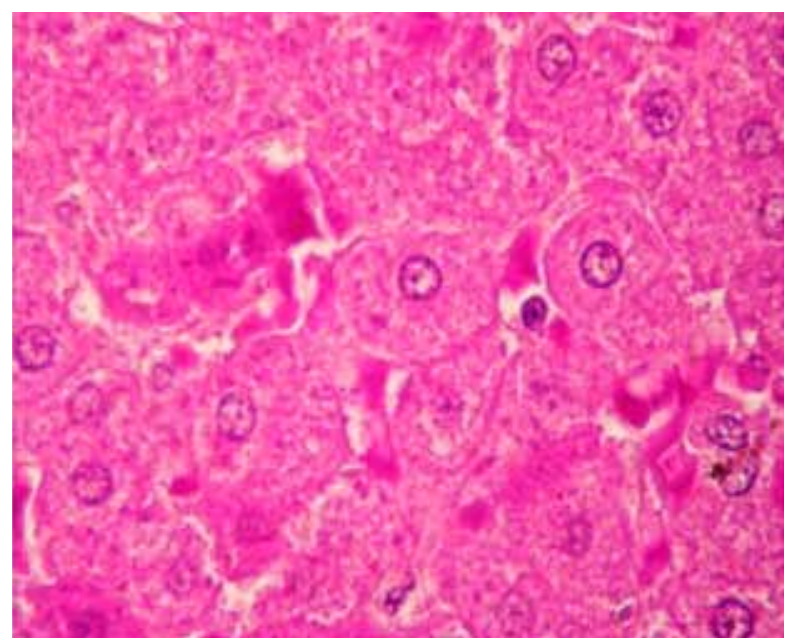

Figura 7. Gránulos de glucógeno. PAS 40X.

según algunos investigadores ${ }^{12}$. En el hígado de cobayo se observaron cordones de una sola célula hepática, que formaban columnas rodeadas por sinusoides vasculares de orientación radial, las cuales se dirigían a la vena centro lobulillar ${ }^{10}$. En el carpincho se observaron cordones formados por una sola célula (Figura 6).

A su vez, las células hepáticas fueron irregularmente poliédricas, de 20 a $25 \mu \mathrm{m}$ de diámetro, aunque en los animales jóvenes fueron de 2 a $7 \mu \mathrm{m}$ menos que en los adultos. Contuvieron un núcleo esférico, frecuentemente doble, de tamaño muy variable. El aspecto varía según su fase funcional, con células pequeñas, turbias y mal delimitadas en los animales en ayunas, en tanto que en los bien alimentados aumentan de tamaño, aparecen bien delimitadas y contienen glucógeno en forma de grumos o gránulos ${ }^{12}$.

En cambio, en el cobayo las células hepáticas son redondas o elongadas, de 17,25 $\mu \mathrm{m}$, con núcleos centrales de 7,31 $\mu \mathrm{m}$ de diámetro, las cuales se ubican en forma de cordones separados por sinusoides, entre los cuales se observan algunos macrófagos y glóbulos rojos $^{3,10}$. En el carpincho, los hepatocitos fueron células poliédricas de tamaño variable, de citoplasma eosinófilo, con un núcleo redondeado central basófilo, con cromatina laxa y nucléolo evidente (Figuras 5 y 6 ).
Los diámetros promedios mayor y menor de los hepatocitos fueron de $21,06 \mu \mathrm{m}$ y $12,37 \mu \mathrm{m}$ respectivamente. El área citoplasmática promedio fue de 191,04 $\mu \mathrm{m}$ y el área nuclear de $24,8 \mu \mathrm{m}$. La relación calculada para núcleo/citoplasma resultó de 0,13 .

En cobayos, a través del método PAS, los hepatocitos revelan la presencia de glucógeno y mucinas neutras con un patrón de tinción variable, algunos de aspecto granulado y otros espumosos y difusos, siendo este último patrón el de mayor frecuencia ${ }^{10}$. En el carpincho, se detectó la presencia de glucógeno con similar aspecto al encontrado en cobayos (Figura 7).

Se concluye que anatómicamente, en $H$. hidrochaeris la separación del hígado en lóbulos está bien delimitada por profundas fisuras. Su lobulación, así como la organización histológica del órgano, resulta similar a la observada en carnívoros. El conocimiento de la estructura hepática permitirá optimizar futuras investigaciones morfo-funcionales.

\section{REFERENCIAS}

1. Acuña F, Resoagli EH, Ortiz M. 2002. Aspectos morfológicos y morfométricos del estómago del carpincho, $H$. hydrochaeris (Linne, 1766). Reunión Comunic Cientif y Tecn UNNE. www.unne.edu.ar, Corrientes, Argentina.

2. Bacha W, Wood L. 2001. Atlas color de histología veterinaria, Ed. Intermédica, Buenos Aires, p.121-164.

3. Bhattacharjya M, Surendrajit K, Banerjee R. 2003. Histological, biometrical and lobar pattern of liver in guinea pig. Geobios 25: 267-275.

4. Bolkovic M, Ramadori D. 2006. Manejo de fauna silvestre en Argentina. Programas de uso sustentable. Publ. Dirección de Fauna Silvestre, Secretaría de Ambiente y Desarrollo Sustentable, Buenos Aires, Argentina, p.168.

5. FAO 2007. El capibara o carpincho (Hydrochoerus hydrochaeris), estado actual de su producción. Publ Depto Agricult FAO, www.produccion-animal.com.ar

6. Frandson R, Spurgeon T. 1995. Anatomía del aparato digestivo. En: Anatomía y fisiología de los animales domésticos, $5^{\circ}$ ed., Interamericana, México, p. 298-324.

7. Getty R. 1982. Sistema digestivo de los carnívoros. En: Anatomía de los animales domésticos, $5^{\mathrm{a}}$ ed., Interamericana, México, p. 1688-1709.

8. König H, Liebich H. 2005. Anatomía de los animales domésticos, $2^{\mathrm{a}}$ ed., Ed. Médica Panamericana, Buenos Aires, p. $15-80$.

9. Romer A. 1973. Anatomía comparada (vertebrados), $4^{\mathrm{a}}$ ed., Ed. Interamericana, México, p. 246-259.

10. Rosas C, Bélgica P, Delsol M. 2010. Histological and histochemical description of the liver of guinea pig (Cavia porcellus). Int J Morphol 28: 151-156.

11. Schwarze E. 1970. El sistema visceral. En: Compendio de anatomía veterinaria, Ed. Acribia, Zaragoza, p. 100.

12. Trautmann A. 1950. Aparato digestivo. En: Histología y anatomía microscópica comparada de los animales domésticos, Ed. Labor, Barcelona, p. 166-256. 